\title{
Cultural Infrastructure and the Planning of Future Cities
}

\author{
Sindhu $S^{l}$, and Reshmi $M K^{1^{*}}$ \\ ${ }^{1}$ BMS College of Architecture, Basavanagudi, Bangalore (India).
}

\begin{abstract}
Culture is an important aspect of human civilization. Preserving and giving value to the cultural heritage of a region can pave the way for local as well as regional development. This includes tangible, intangible and the natural heritage of cities. It is necessary to develop a cultural infrastructure plan along with other aspects such as transportation, built, green and grey in frastructure. Cultural infrastructure refers to places where culture is experienced, participated in or showcased in. This includes the existing cultural heritage of a place as well as the planning of spaces for cultural stimulation and involvement. With the advent of fourth industrial revolution smart cities are gradually becoming the way of life across the world. The Smart City uses Information and Communication Technology (ICT) and Internet of Things (IoT) to effectively manage transportation, water services, waste disposal, energy and other community services. In this scenario it becomes imperative to have strategic infrastructure planning. Indian Government has recently launched the Smart City Mission in India and several smart city projects are underway across the country. It becomes necessar y in this context that Indian cities with their rich tradition and cultural heritage do not lose their unique identity in this process of transformation into smart cities. Even as smart city projects stress the need for heritage preservation there is a lot of ambiguity in how they can be integrated and used to advance urban intelligence. The technologies of the smart city have considerable potential to be used for the management and enhancement its cultural heritage and can help in the creation of a cultural infrastructure plan. This paper will examine the significance of cultural infrastructure in future cities and how it can be integrated into the city planning process of Indian cities through the study of relevant case studies from around the world.

Keywords: Cultural infrastructure, Heritage, Smart cities, City planning
\end{abstract}

\section{Introduction}

As the world is getting increasingly urbanized there is a lot of pressure on the existing urban infrastructure and especially on the older heritage cities. As new cities are being planned and existing urban areas are getting renewed in the urban development process cultural infrastructure is usually given the least importance. The advent of newer technologies and emergence of smart cities have presented several opportunities in urban development. But as cities across the world are getting smarter the cultural aspect of cities are many times not given much consideration especially in the context of Indian cities.

The cultural heritage in cities can be categorised as i)Tangible :- This includes movable heritage such as paintings, sculptures etc as well as mmovable heritage such as monuments and historical sites.

ii)Intangible :- This includes oral traditions, performing arts, festivals, customs and rituals.

iii)Natural :- This include natural features with cultural associations, geological formations including rocks, hills etc, sacred groves etc.

\footnotetext{
Corresponding author: reshmimk@gmail.com
}

All these above categories can be found in varying ratios in all urban areas. They usually coexist along with modern infrastructure and give unique identities to the cities. They also form the crux around which the cultural life of the city revolves. They are aided in this by other structures including museums, art galleries, open spaces etc which together form the cultural infrastructure in the city.

Smart city concept is a comparatively recent trend where the ICT and IoT is being used in the urban development process. Vast amounts of data are collected and organized and made accessible to the population which enables sustainability and better management of cities. This can be used to enhance various aspects of cities including transportation, environment and overall well being of people. Smart city initiatives should be adapted to to the local context, building on existing assets of the city and the identity of place (Angelidou, 2016)

\section{Cultural Infrastructure}

Cultural heritage both old as well as new form important narratives in the city. But unfortunately these spaces are 
rehearsal areas or any space where art, music or any other creative endeavours are generated. They can be full time or part time, single purpose or multipurpose, historical or contemporary structures or spaces. They can be either built for purpose or adaptively reused.

A cultural infrastructure plan helps to support and enhance these cultural spaces in a city. It becomes very important to recognize and incorporate this aspect into the planning process of cities by conserving and highlighting existing cultural assets in the city and at the same time planning and incorporating cultural spaces into future cities which will contribute to enhance creativity. The importance of a Cultural Infrastructure Plan is being recognized by many cities including London, Amsterdam and Toronto. Indian cities with their rich cultural heritage are yet to recognize the necessity of a Cultural Infrastructure Plan.

\section{The Smart City}

\subsection{The concept of smart cities}

The Smart City is the realization of Fourth Industrial Revolution in the spatial context. In Smart Cities 'People to People', 'People to Things' and 'Things to Things' are connected in real time. Data collected from the citizens, devices and other assets are used to effectively manage the city. The Smart City uses Information and Communication Technology (ICT) and Internet of Things (IoT) to effectively manage transportation, water services, waste disposal, energy and other community services.

\subsection{The Indian Scenario}

India is the fastest growing economy and the second largest populated country in the world. The educated human resource that it posseses makes India one of the key players in shaping the fourth industrial revolution. As a part of the procedure towards e-governance India has been steadily enrolling its citizens into it's national database. Aadhar is the largest biometric database in the world.

The recent smart phone revolution and India's software capabilities enable it to maintain the position as an IT Superpower and 'info-nation'. India has been able to capitalize on the third industrial revolution and starting in the 1980's has managed to become a leading sourcing destination for the global IT industry. India also has the highest e-commerce market and the highest number of technological start ups.

Prime Minister Narendra Modi recently announced the creation of Centre for Fourth Industrial Revolution at the World Economic Forum meeting in order to take advantage of this situation and steer India as one of the frontrunners in this revolution. The centre which will be based in Delhi will be part of a network which includes USA, China and Japan and will be collaborating with the National Institute for Transforming India (NITI) . The centre will be preparing protocols and policies for emerging technologies mainly focusing on artificial intelligence, blockchain and drones.

India today is a country with the highest growth of internet access and has also managed to digitize its economic, social and political systems at an unprecedented scale. National Association of Software and Services Companies (NASSCOM) estimates that AI has the potential to contribute $\$ 957$ billion to the Indian

Economy according to the Artificial Intelligence Primer 2018. Th main sectors which would benefit from AI would be agriculture, education, healthcare and infrastructure.

\subsection{The Smart City Mission in India}

'100 Smart Cities' mission was launched by the Government of India in 2016. According to the Smart City Mission, these cities will have:

i) adequate water supply,

ii) assured electricity supply,

iii) sanitation, including solid waste management,

iv) efficient urban mobility and public transport,

v) affordable housing

vi) IT connectivity and digitalization,

vii) good governance, especially e-Governance and citizen participation,

viii) sustainable environment,

ix) safety and security of citizens, particularly women, children and the elderly, and

$\mathrm{x})$ health and education.

100 cities have been selected so far for this mission and work is underway in most of these cities. It is still a work in progress and will take few more years for the work to get completed.

\section{Cultural Infrastructure In Smart Cities}

Cultural Infrastructure plan in any city should recognize and address the local context. These should include smaller and larger hubs which nurture talent and also facilitate community connections and social cohesion. 


\subsection{Cultural Infrastructure in Smart City London}

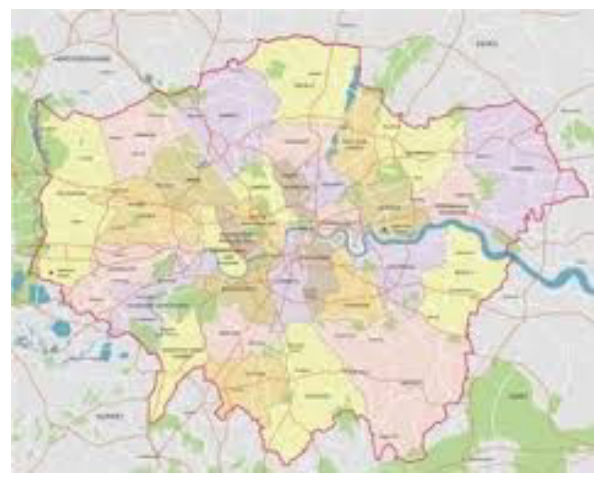

Fig. 1: Map of London (Source : London.gov.uk)

London is one of the oldest cities in the world. Situated on the banks of River Thames it has several historic layers.

\subsubsection{Smart City Master Plan}

London has set the goal to be the smartest city by the year 2020. Smart City London Plan has five key aims which include
i) User centered designs
ii) Open and secure city data
iii) Connectivity and Smarter streets
iv) Digital capability improvement of citizens
v) Smart City Collaboration

\subsubsection{Smart City Master Plan}

London has been a city which has been a frontrunner in developing a Cultural Infrastructure Plan in order to nurture creativity and has recently released Cultural Infrastructure Plan which is being planned alongside the smart city plan. The cultural infrastructure plan focuses on cultural spaces and how the Capital should best plan to meet its cultural needs

The seven prong action plan recently released by the Greater London Authority include the following points.
Understanding location of existing cultural infrastructure through a cultural infrastructure map.

ii)

Planning and designing new cultural infrastructure

iii) Providing infrastructure for a world class city

iv) Increasing investment

Policies to enable culture and creative industries

vi)

\section{Providing training and networking}

Cultural Infrastructure map helps to locate cultural infrastructure along with transport. Planning and demographic data. The user scan download information from this interactive map and also suggest missing infrastructure as well as edit information on existing infrastructure, check travel times etc.

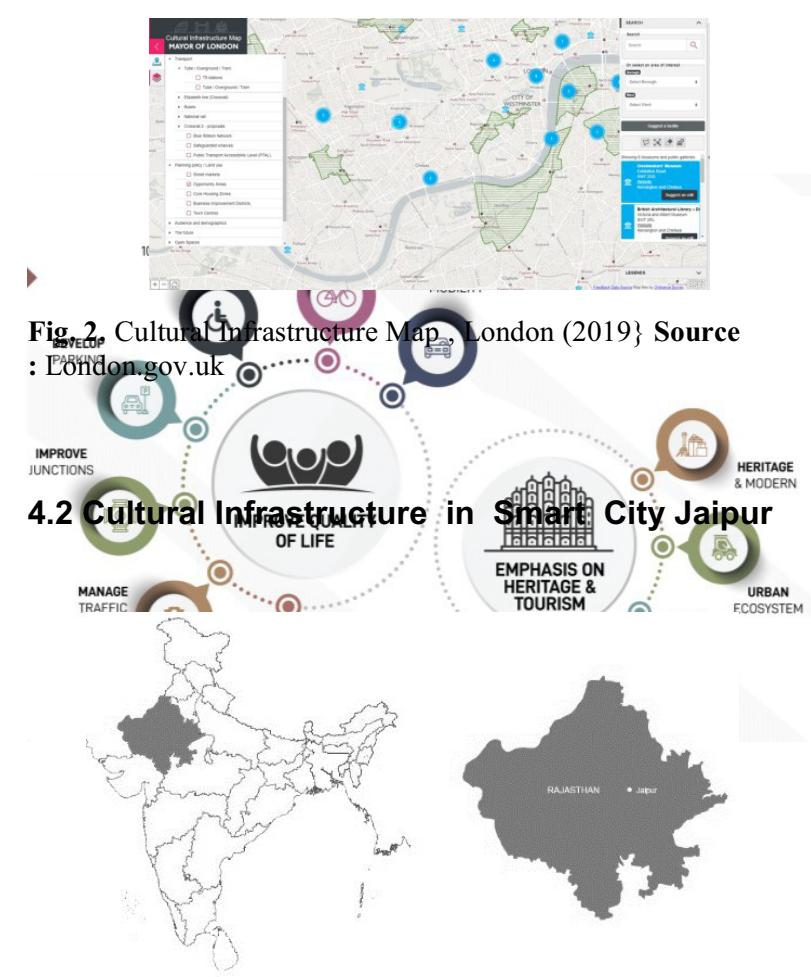

Fig. 3: Rajasthan State is located in northwestern part of India. Jaipur is situated in the east-central part of the state.

\subsubsection{JAIPUR-History and Background}

It was built by the Maharajah Sawai Jai Singh II. In 1727, Jaipur replaced Amber as the capital of Rajasthan due to the growing population and increasing scarcity of water. The suitability of the terrain, righteous defensive position, communication, and availability of water made Jaipur a suitable location for the new capital.

The new city capital comprised of huge fortification walls 
along with seven strong gates. The town planning of Jaipur was very advanced for its time and the best in the Indian subcontinent in that period. When the Prince of Wales visited Jaipur in

1853 the whole city was painted pink to welcome him. Even today the buildings in the city are painted pink and give a distinctive appearance to the city.

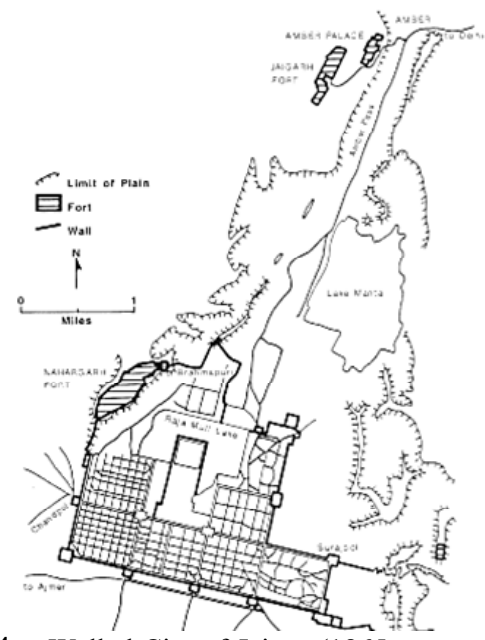

Fig. 4 - Walled City of Jaipur (1865 map of Jaipur) Source : Survey of India

The emergence of British government led to expansion of the city as they setup their agencies within fort resulted in walled city being moved out as the rapid growth could not be accommodated in the existing structure and the city couldn't cope with the force thrust on it. The expansion led to destruction of socioeconomic structure, centripetal to centrifugal to suburbs, Dualism - old and new by the band of low status housing, cultural problem and haphazard growth.

And later the city has been expanding and evolving over a period of time yet retaining the cultural Identity of the city.

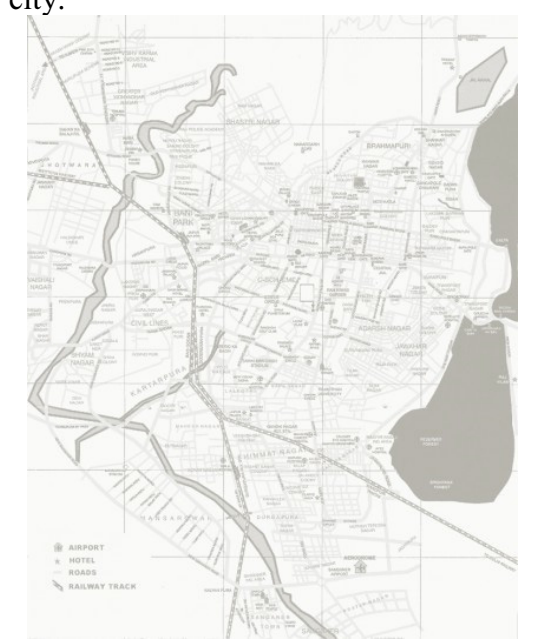

Fig. 5. Expanded City of Jaipur

\subsubsection{Smart city initiatives in Jaipur}

Jaipur Along with New Delhi and Agra which both lie approximately $250 \mathrm{~km}$ away, it forms the 'Golden Triangle' tourist circuit.

Among the list of the 109 smart cities of the country,
Jaipur is one of those aspiring small cities which has been chosen by the Smart City Mission of Ministry of Urban Development (MoUD), Government of India launched in June 2015.

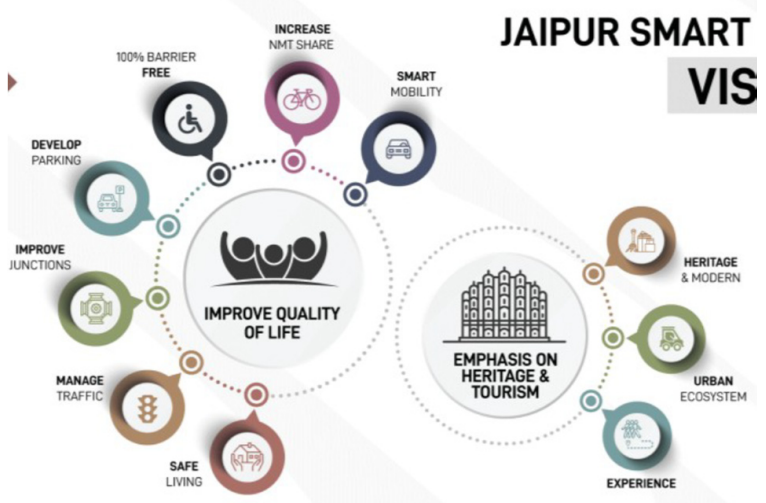

Fig. 6 : Jaipur Smart City - Vision Source : Jaipur Smart City LTD

\subsubsection{Smart city: Cultural Infrastructure and treatment of heritage structure - blending modernity with Heritage}

Smart city initiative for Heritage and Tourism serves as the purpose for protection of the cultural heritage, but also attracts tourism and promotes the economy of the place. Thus, important tourist destinations are also major urban centers and it is essential to protect the urban identity. Rajasthan is one of the major tourist destinations in the country because it has a large cultural resource.

The 18th century city of Jaipur city known for its architectural beauty and vibrant culture, is moving towards syncing its historic magnificence with modernity, as projects under the Centre's Smart City Mission gain momentum. The ancient walled city has been chosen for Area-Based Development under the Smart City Mission where a blend of heritage with modernity is taking shape through various projects such as :

\begin{tabular}{c}
\hline $\begin{array}{c}\text { Restoration and Adaptive reuse of heritage } \\
\text { structures }\end{array}$ \\
\hline Rejuvenation of Talkatora lake, Baoris \\
\hline $\begin{array}{c}\text { Heritage walks and Bazaar Street facade } \\
\text { improvements, green roof tops }\end{array}$ \\
\hline $\begin{array}{c}\text { Integration with common mobility card for } \\
\text { monument entry payments }\end{array}$ \\
\hline $\begin{array}{c}\text { Heritage App with QR Code for monument } \\
\text { information }\end{array}$ \\
\hline Training and rating of Tourist guides, \\
Tourism Police \\
\hline $\begin{array}{c}\text { Promotion of traditional handicraft and textile } \\
\text { workers }\end{array}$ \\
\hline Night market and vending zones \\
\hline Tourist interpretation centre
\end{tabular}




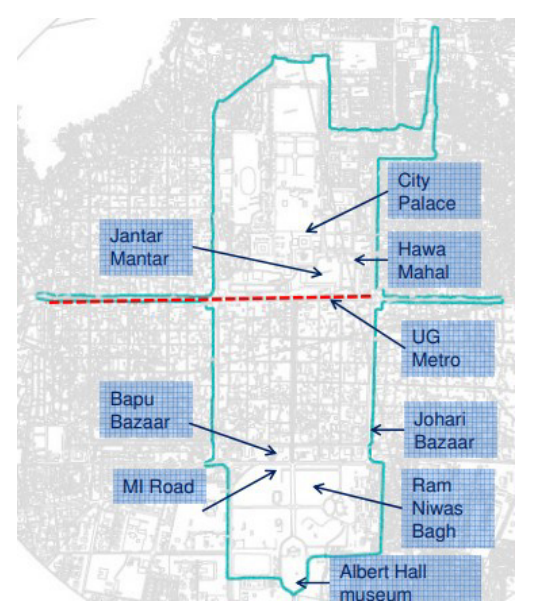

Fig. 7 : The chosen area for area based development is two chowkries of the walled city. Source : Jaipur smart city proposal

\section{Conclusion:}

Cultural infrastructure is an essential component of cities and should necessarily be a part of smart city initiatives. Heritage structures are important aspects of this infrastructure. There are several ways through which cultural heritage can be assimilated as part of smart city projects. Smart city applications can be crucial in the monitoring and management of heritage and this has been effectively incorporated in several cities in Europe and America. Indian smart cities are yet to incorporate this effectively into their planning process. As seen in the Jaipur case study there are initiatives being taken in a few cities, but most smart city projects are doing very little to fully utilize the potential of smart technologies and develop of the cultural infrastructure in those cities. The value of cultural infrastructure and heritage management need to be given more emphasis in the ongoing and upcoming smart city initiatives in India. Each city should develop a cultural infrastructure plan which should be implemented along with other developmental activities. The cultural aspect of vibrant Indian cities should not be ignored in the urban development process as it brings vitality and unique identity to these cities.

\section{References}

1.M.Angelidou, The International Archives of the Photogrammetry, Remote Sensing and Spatial Information Sciences, XLII, (2017)

2.Angelidou, M, Int. Jrnl. of Social Science Studies, 18, (2016)

3.Greater London Authority, Cultural Infrastructural Plan (2019)

4.Riganti, Int. Jo. for Arch. Res. , 16, (2017) 